\title{
An overview of injuries to adolescents and young adults related to substance use: data from Canadian emergency departments
}

\author{
Sarah Lea, MSc; ${ }^{*}$ Karen Black, $\mathrm{MD}, \mathrm{MSc}_{;}^{\dagger}$ Mark Asbridge, $\mathrm{PhD}^{*}$
}

\section{ABSTRACT}

Objective: Alcohol is a significant risk factor for injury, and is one of the leading causes of death, disability and premature mortality among young Canadians. This paper provides an overview of alcohol-related injury among adolescents and young adults presenting to Canadian emergency departments (EDs).

Methods: We reviewed records from the Canadian Hospitals Injury Reporting and Prevention Program database during the 4-year period between 2000 and 2003. We included individuals younger than 25 years who presented to EDs in 11 pediatric and general hospitals with injuries for which alcohol, either alone or in conjunction with drugs, was recorded as a contributing factor. We examined key socio-demographic and injury-related factors associated with alcohol and drugrelated injuries, including intent and disposition.

Results: Alcohol was identified as a factor in 2389 injuries during this 4 -year period; $408(17 \%)$ of these cases also involved drug use. Approximately $55 \%$ of these patients were male and the majority was between 15 and 19 years of age. Unintentional injuries were the most common presentation, self-harm injuries were more common among female patients and violence-related injuries were more common among male patients. Most patients received treatment for their injuries. However, as age increased, outcome differences were observed between sexes.

Conclusion: Alcohol-related injuries are increasing among Canadian youth. These findings highlight the importance of obtaining thorough drug and alcohol histories and measurement, when appropriate, for adolescents and young adults presenting to EDs with injuries.

Keywords: alcohol, drugs, injury and trauma, emergency department, youth and young adults

\section{RÉSUMÉ}

Objectif : L'alcool est un important facteur de risque de blessure et l'une des principales causes de décès, d'invalidité et de mortalité prématurée chez les jeunes Canadiens. Cet article présente un survol des blessures liées à l'alcool chez les adolescents et les jeunes adultes se présentant dans les services d'urgence canadiens.

Méthodes : Nous avons passé en revue les dossiers de la base de données du Système canadien hospitalier d'information et de recherche en prévention des traumatismes (SCHIRPT) pour la période de 4 ans allant de 2000 à 2003. Les sujets avaient moins de 25 ans et avaient consulté au service d'urgence de 11 hôpitaux pédiatriques et généraux pour des blessures liées à l'alcool, consommé seul ou avec des médicaments, l'alcool étant ici perçu comme un facteur contributif. Nous avons analysé les principaux facteurs sociodémographiques et lésionnels associés aux blessures découlant de la consommation d'alcool et de drogues, y compris l'intention et le caractère délibéré des gestes.

Résultats : L'alcool a été reconnu comme facteur contributif dans 2389 blessures au cours de la période de 4 ans, 408 (17\%) de ces cas impliquaient également la consommation de drogues. Environ $55 \%$ de ces patients étaient de sexe masculin, et la majorité avait entre 15 et 19 ans. Les blessures accidentelles constituaient le motif le plus fréquent de consultation; les automutilations s'observaient plus fréquemment chez les femmes et les blessures liées à des actes de violence, chez les hommes. La plupart des patients ont reçu un traitement pour leurs blessures; toutefois, on a observé certaines différences entre les sexes selon l'âge.

Conclusion : Les blessures liées à la consommation d'alcool sont en hausse chez les jeunes Canadiens. Cette observation rappelle l'importance d'obtenir I'historique et les dosages complets de la consommation de drogues et d'alcool, selon le cas, chez les adolescents et les jeunes adultes qui se présentent à l'urgence pour des blessures.

\section{INTRODUCTION}

Injury is one of the leading causes of morbidity and premature mortality among young Canadians. ${ }^{1-3}$ Alcohol use is a significant risk factor for injury, and national

From the Departments of ${ }^{*}$ Community Health and Epidemiology, and tEmergency Medicine and Pediatrics, Dalhousie University, Halifax, NS

Submitted Feb. 12, 2008; Revised Aug. 25, 2008; Accepted Nov. 26, 2008

This article has been peer reviewed.

CJEM 2009;11(4):330-6 
organizations such as the Canadian Public Health Association, the US Center for Disease Control and the World Health Organization have identified it as an important risk factor and focus for prevention strategies. ${ }^{4-6}$ An extensive international literature review found that injured individuals are more likely than noninjured individuals to have a positive blood alcohol concentration and to report alcohol consumption before the injury event. . $^{2,-9}$

Studies investigating unintentional injuries have found that alcohol substantially increases the risk of falls, motor vehicle collisions and drowning. ${ }^{10-15}$ Such investigations have found exposure rates ranging from $13 \%$ to $37 \%$ among persons injured in nonfatal falls, and rates between $27 \%$ and $47 \%$ for drowning victims. ${ }^{13}$ Alcohol consumption is also strongly related to intentional injuries, particularly violent injury and injury related to self-harm. ${ }^{16-18}$ A number of studies of suicide and self-harm have noted alcohol as a key factor, particularly among adolescents and young adults. ${ }^{16,19-24}$

Adolescents and young adults disproportionately suffer the burden of injury, with unintentional injury representing more than $40 \%$ of all deaths for Canadians younger than 24 years. ${ }^{1}$ In addition, alcohol is the most frequently used drug among young Canadians; approximately $81 \%$ of individuals between the ages of 15 and 24 years reported past-year drinking in $2004 . .^{25}$ The concurrent high risk of injury and alcohol consumption among adolescents and young adults suggests that additional attention is warranted for this group with respect to prevention efforts.

Only a handful of studies have explored the prevalence of alcohol consumption among youth presenting to EDs. In a study of 134 adolescents (81\% male) presenting to the ED and admitted to a US trauma centre, $34 \%$ tested positive for alcohol or drugs. ${ }^{26}$ Using data from the $\mathrm{Na}$ tional Electronic Injury Surveillance System, investigators found that $3.2 \%$ of total ED visits in the United States by youth aged 13 to 25 years were alcohol-related. Male youth represented $61 \%$ of all ED visits, $69 \%$ of all alcohol-related visits and were 1.4 times more likely to have alcohol-related injuries than female youth. ${ }^{\text {? }}$

By employing administrative data that was captured in the Canadian Hospitals Injury Reporting and Prevention Program (CHIRPP) data set, we aimed to provide an overview of alcohol and drug-related injuries among adolescents and young adults in Canada. The knowledge of the presence of alcohol, other drugs or both is important in the evaluation of trauma patients, and in the identification of individuals at risk of potentially serious alcohol problems and future alcohol-related injuries. ${ }^{8}$

\section{METHODS}

\section{Study design, setting and population}

Data for this project were obtained from CHIRPP for the period between Jan. 1, 2000, and Dec. 1, 2003. CHIRPP is an ongoing ED-based injury surveillance system that was established in 1990 and operates in 10 pediatric and 4 general hospitals across Canada. Standardized data are collected from injured patients at each site, and a number of socio-demographic and eventrelated details are obtained. The data were compiled from self-administered questionnaires at the Child Injury and Maltreatment Section of the Health Surveillance and Epidemiology Division, Centre for Healthy Human Development, Health Promotion and Chronic Disease Prevention Branch of the Public Health Agency of Canada.

Briefly, a self-administered questionnaire was provided to all injured patients or parents upon their presentation to the ED. The questionnaire inquired about the circumstances of the injury, including event details, patient demographics and substance use. The attending physician then completed a medical questionnaire containing information about the nature of the injury, the body part injured, suspected substance use, intent and patient disposition.

\section{Study outcome and covariates}

The key outcome measure was injury with suspected alcohol involvement, either alone or in conjunction with drug use. To identify all cases involving alcohol, we examined records of all injuries to people younger than 25 years that occurred during this time period. We selected records in which alcohol ("alcohol [beverage], one type" or "multiple types of alcohol [beverage]") was indicated as a factor in the injury event. This process identified 2394 cases. Using an iterative process, we eliminated duplicate cases, cases that were coded incorrectly or cases that had too little information. This process led to the removal of 5 cases, leaving 2389 cases in which "alcohol" or "alcohol and other drugs" were identified as factors in the injury.

The variable "substance" was created to clarify what substances the patient was using at the time of injury. If the narrative clearly indicated alcohol only, the variable substance was coded "alcohol." If the narrative clearly indicated alcohol and other drugs, or alcohol and suspected drug use, then the variable substance was coded "alcohol and other drugs." The variable did not 
distinguish between medications, street drugs and other abused products.

Socio-demographic characteristics, including age group, sex, location of injury (i.e., home, bar, road or other location), day of the week (i.e., weekday or weekend), season (i.e., summer, fall, winter or spring), region (i.e., Atlantic [Newfoundland and Labrador, Nova Scotia], Central [Ontario, Quebec] or Western [British Columbia, Alberta, Manitoba]), substance use (i.e., alcohol or alcohol and other drugs), intent of injury (i.e., unintentional, violence-related or self-harm) and injury disposition (i.e., no treatment, treatment and then released, or admitted) were evaluated. Injury outcome was used as a proxy estimate for injury severity, which had been documented previously by several authors analyzing CHIRPP data. ${ }^{27,28}$

\section{Data analysis}

Data analysis involved generating descriptive statistics to provide an overview of the 2389 alcohol-related injuries in the CHIRPP database. We used $\chi^{2}$ tests for subgroup trends to compare groups across a number of variables, with $p<0.01$ interpreted as significant. Preliminary results indicated that age was a strong confounder, so all analyses were stratified by age group (i.e., $<15 \mathrm{yr}, 15-19$ yr or 20-24 yr). All analyses were performed using SAS Version 9.1 (The SAS Institute). Ethical approval for the study was obtained from the Office of Research Ethics at Dalhousie University.

\section{RESULTS}

During the 4-year study period, 393328 patients presented to CHIRPP hospitals, and $2389(0.6 \%)$ of all injuries were alcohol-related. The proportion of injuries in which alcohol was involved increased each year between 2000 and 2003; the noticeable increases in prevalence were observed among older individuals (Table 1).
For example, during the period from 2000 to 2003 the prevalence of alcohol-related injuries among individuals younger than 15 years increased from $0.15 \%$ to $0.25 \%$. Among individuals aged 15 to 19 years, the prevalence increased from $1.87 \%$ to $3.10 \%$; and among those aged 20 to 24 years, alcohol-related injuries increased from $3.05 \%$ in 2000 to $5.69 \%$ in 2003 .

Approximately $55 \%$ of individuals in the data set were male and the majority of patients were 15-19 years of age (Table 2). A larger proportion of the youngest age group was female $(58 \%)$ and as age increased this trend reversed. For all age groups, other locations (e.g., schools, parks, public places) were the most common location of injury; for the 2 younger age categories, home was the second most common location; and for older individuals, it was a bar setting.

The majority of alcohol-related injuries occurred on the weekend and this was generally consistent across all 3 age groups. Among those younger than 15 years, spring was the season with the greatest proportion of individuals presenting with alcohol-related injuries, whereas for those aged 15-19 years it was summer, and for those aged 20-24 years it was fall.

Examination of the patient narrative, the physician report or both, indicated that a majority $(83 \%)$ of patients reported the use of alcohol alone. Among the 2 younger age groups, the proportion of patients presenting with alcohol and other drugs was $20.2 \%$ and $19.8 \%$, respectively. Yet, among individuals 20-24 years of age only $7 \%$ of injuries involved the use of alcohol and other drugs.

Unintentional injuries were most common for both male $(67 \%)$ and female $(75 \%)$ youth across all age groups, although the proportion of unintentional injuries decreased with increasing age (Fig. 1). For intentional injury involving alcohol, self-harm injuries (14\%) were significantly more common among female youth of all age groups, and violence-related injuries were predominately an issue for male youth 15 years and older (23\% and $45 \%$, respectively).

Table 1. Prevalence of alcohol-related injuries by age group from Jan. 1, 2000, to Dec. 31, 2003

\begin{tabular}{|c|c|c|c|c|c|c|c|c|}
\hline \multirow{2}{*}{$\begin{array}{l}\text { Year } \\
2000\end{array}$} & \multicolumn{8}{|c|}{ Age group; no. (\%) of alcohol-related injuries/total* no. of injuries } \\
\hline & 121/82 590 & $(0.15)$ & 223/11 894 & $(1.87)$ & $114 / 3743$ & (3.05) & $458 / 98227$ & $(0.47)$ \\
\hline 2002 & 169/83 633 & $(0.20)$ & $313 / 12644$ & $(2.48)$ & $128 / 3650$ & (3.51) & 610/99 927 & $(0.61)$ \\
\hline 2003 & 206/82 743 & $(0.25)$ & 406/13 110 & (3.10) & $190 / 3337$ & (5.69) & $802 / 99189$ & $(0.81)$ \\
\hline
\end{tabular}


Using disposition as a general proxy of injury severity, ${ }^{28}$ these data demonstrate that most ED patients received treatment for their alcohol-related injuries and this proportion increased with age (Fig. 2). Male youth younger than 15 years represented the greatest proportion of admitted patients; however, as age increased, the proportion of admitted male patients decreased and a greater proportion of female patients were admitted.

Of the 2389 alcohol-related injuries, 1981 involved only alcohol and 408 involved alcohol in combination with other drugs (Table 3). Despite the majority of presentations involving alcohol alone, female youth were more likely than male youth to present with use of alcohol and other drugs $(p<0.01)$. Similarly, a greater proportion of youth younger than 15 years presented with use of alcohol and other drugs, and a very small proportion of youth aged 20-24 consumed alcohol and other drugs at the time of their injury. Although the majority of unintentional injuries involved alcohol alone, the pattern among intentional injuries was less clear. Of the 482 violence-related injuries, $22.7 \%$ involved alcohol alone, and $37.5 \%$ of self-harm $(n=224)$ injuries involved the consumption of alcohol along with other drugs. Finally, a greater proportion of those presenting with injuries involving alcohol and other drugs were admitted (39.2\%) rather than being treated and released, or not treated at all.

\section{DISCUSSION}

The purpose of this study was to examine injuries involving alcohol, either alone or consumed with drugs, among adolescents and young adults presenting to Canadian EDs that participate in the CHIRPP network. Overall, although the proportion of alcohol-related injuries was small, these proportions increased across all age groups between 2000 and 2003, which coincides with increased rates of substance use among young people in Canada over the past decade..$^{25}$ Moreover, as age increased, so did the proportion of drug use and the severity of injury as measured by admission disposition.

The low prevalence of alcohol-related injuries during the 4-year period may be because large numbers of individuals younger than 15 years were included in the

Table 2. Socio-demographic characteristics of all alcohol-related injuries from the Canadian Hospitals Injury Reporting and Prevention Program database, Jan. 1, 2000, to Dec. 31, 2003

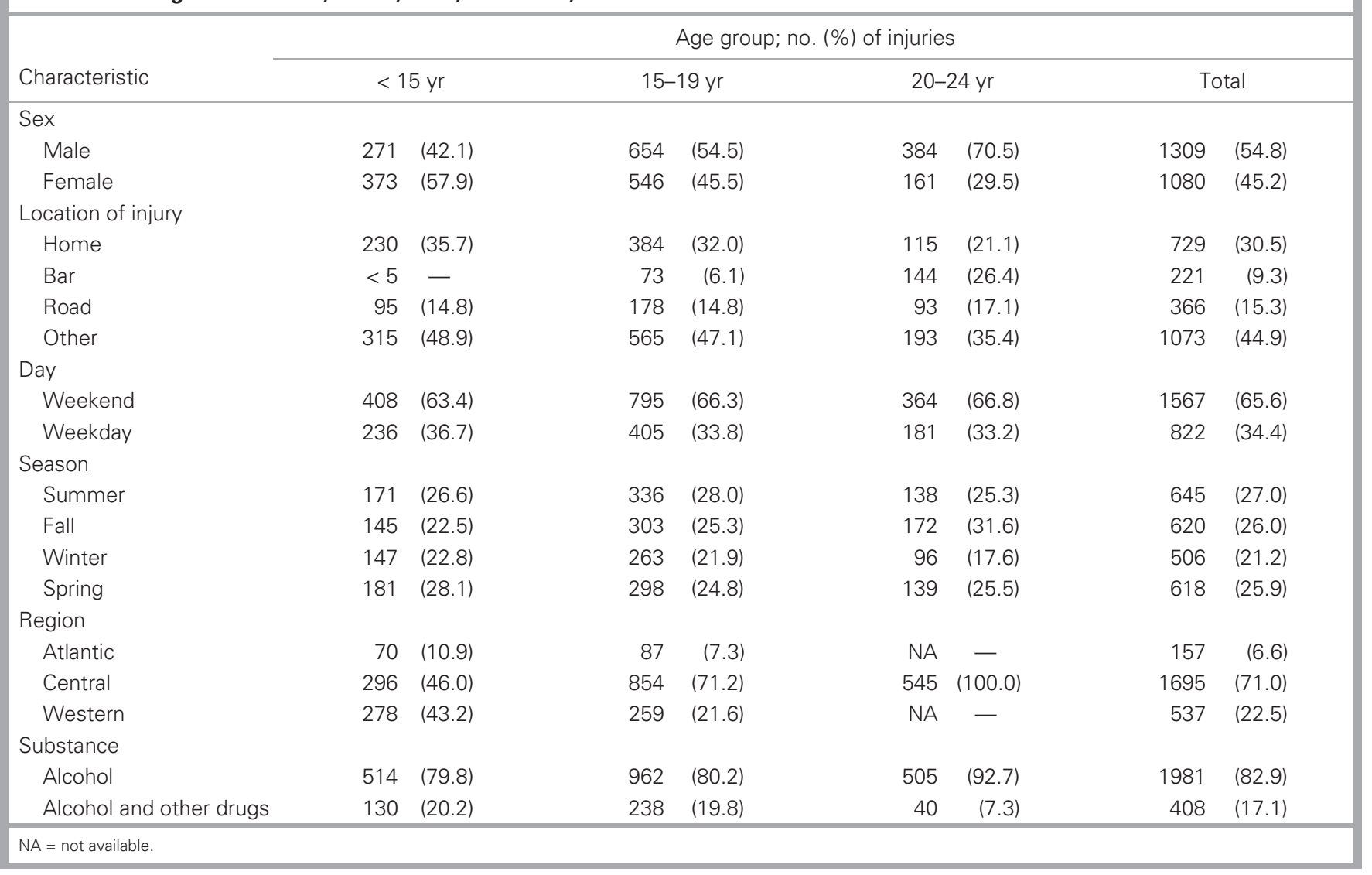


sample (80\%). The occurrence of alcohol-related injuries among individuals younger than 15 years combined with the fact that the CHIRPP data set does not identify who consumed the substance raises concerns of who may have caused the injuries. One must consider not only youth who are themselves consuming alcohol and drugs, but also the possibility of adults and other individuals, such as the youth's friends or family, who may have consumed substances and whose behaviour led to the injury event.

When examined by age, alcohol-related injuries represented less than $1 \%$ of total injuries among those younger than 15 years, $2 \%-3 \%$ among individuals $15-19$ years of age and 3\%-6\% among individuals 20-24 years of age. Age-specific findings were consistent with other ED studies of alcohol-related injuries among adolescents in the United States and Australia., ${ }^{7}$

Overall, more male than female youth presented with alcohol-related injuries, which is consistent with the

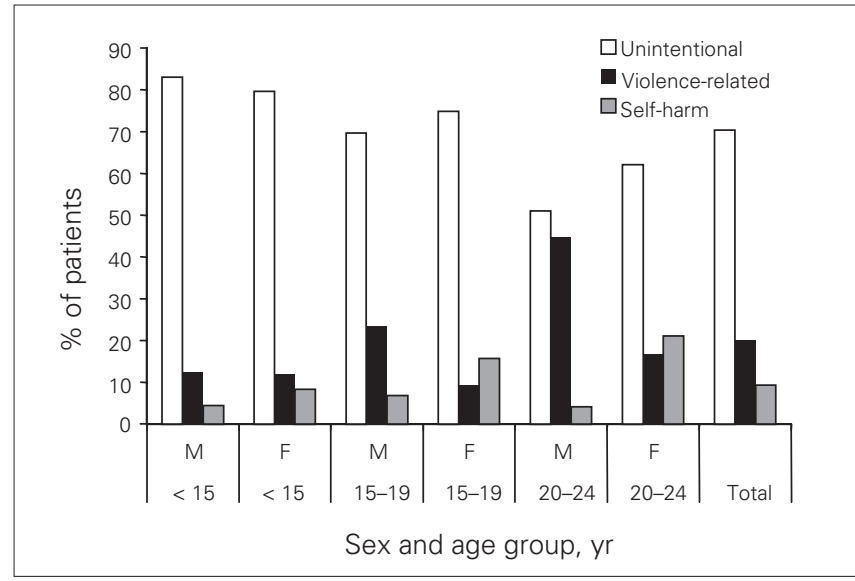

Fig. 1. Frequency of intent of alcohol-related injuries by sex and age group.

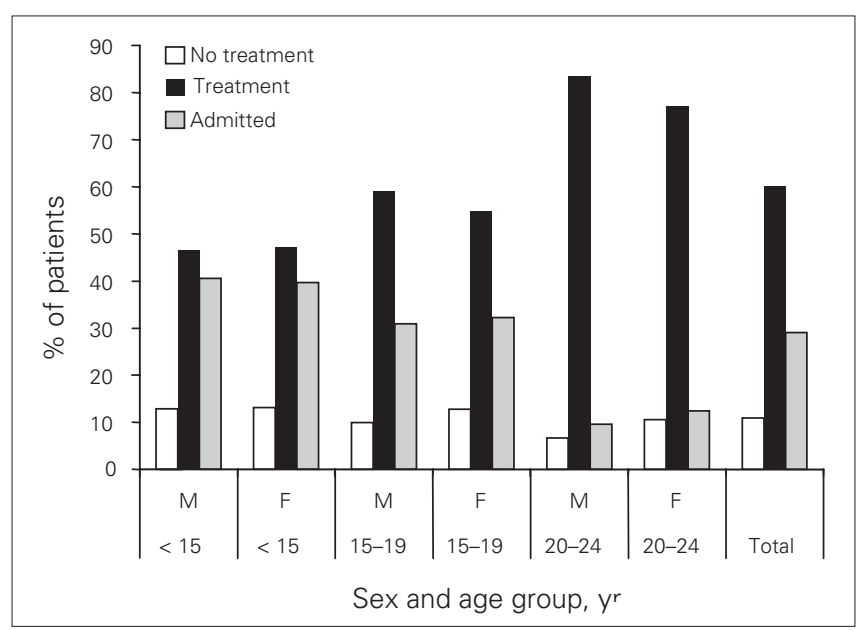

Fig. 2. Frequency of disposition of alcohol-related injuries by sex and age group. existing evidence. ${ }^{7,29}$ There was, however, a higher proportion of female youth (45\%) in the CHIRPP data relative to other studies, which may be a result of the high proportion of alcohol-related injuries among young ( $\leq 15 \mathrm{yr}$ ) female youth. ${ }^{7,29}$ Although unintentional injury was the most common for both male and female youth, the second most common intent for male youth was violence-related, and for female youth was self-harm. These results support the broader literature on the role of alcohol as a known risk factor for intentional injuries, ${ }^{18,30,31}$ and to the unique role that alcohol plays in the injury experiences of male and female youth. ${ }^{21-23}$ These findings suggest that injury prevention programs should recognize the differences between the effect of alcohol use on injury outcomes in male and female youth.

The role of substances other than alcohol in injury events has received greater attention in recent years. ${ }^{21,25,32}$ In our study, injuries involving alcohol and other drugs were more common among younger female youth,

\begin{tabular}{|c|c|c|c|c|}
\hline \multirow[b]{2}{*}{ Variable } & \multicolumn{3}{|c|}{ No. (\%) of alcohol-related injuries } & \multirow[b]{2}{*}{$\begin{array}{l}p \text { value }{ }^{*} \\
\left(\chi^{2} \text { test }\right)\end{array}$} \\
\hline & \multicolumn{2}{|c|}{ Alcohol } & $\begin{array}{l}\text { Alcohol and } \\
\text { other drugs }\end{array}$ & \\
\hline \multicolumn{5}{|l|}{ Location of injury } \\
\hline Home & 586 & $(29.6)$ & 143 (35.1) & $<0.01$ \\
\hline Bar & 215 & $(10.9)$ & $6 \quad(1.5)$ & \\
\hline Road & 325 & $(16.4)$ & $41 \quad(10.1)$ & \\
\hline Other & 855 & $(43.2)$ & 218 (53.4) & \\
\hline \multicolumn{5}{|l|}{ Day } \\
\hline Weekend & 1338 & $(67.5)$ & $229(56.1)$ & $<0.01$ \\
\hline Weekday & 643 & (32.5) & 179 (42.9) & \\
\hline \multicolumn{5}{|l|}{ Season } \\
\hline Summer & 542 & $(27.4)$ & 103 (25.3) & 0.53 \\
\hline Fall & 517 & $(26.1)$ & 103 (25.3) & \\
\hline Winter & 409 & $(20.7)$ & 97 (23.8) & \\
\hline Spring & 513 & $(25.9)$ & 105 (25.7) & \\
\hline \multicolumn{5}{|l|}{ Region } \\
\hline Central & 1453 & (73.4) & 242 (59.3) & $<0.01$ \\
\hline Atlantic & 122 & $(6.2)$ & $35 \quad(8.6)$ & \\
\hline Western & 406 & (20.5) & 131 (32.1) & \\
\hline \multicolumn{5}{|l|}{ Intent of injury } \\
\hline Unintentional & 1459 & $(73.7)$ & 224 (54.9) & $<0.01$ \\
\hline Violence-related & 451 & $(22.8)$ & $31 \quad(7.6)$ & \\
\hline Self-harm & 71 & (3.6) & 153 (37.5) & \\
\hline \multicolumn{5}{|l|}{ Disposition } \\
\hline Not treated & 217 & $(11.0)$ & 45 (11.0) & $<0.01$ \\
\hline Treated & 1231 & $(62.1)$ & 203 (49.8) & \\
\hline Admitted & 533 & (26.9) & 160 (39.2) & \\
\hline
\end{tabular}

${ }^{*} p$ value refers to the difference between alcohol $v$. alcohol and other drugs. 
specifically among those presenting with intentional selfharm injuries, and were also more severe, with a greater proportion leading to hospital admission. Moreover, injuries involving alcohol and other drugs required admission to hospital more often than those involving alcohol alone. Again, this may be explained by the relationship between substance use and intent of injury, as injuries involving alcohol and other drugs were more likely to be intentional than injuries involving alcohol alone.

\section{Limitations}

There are several limitations to our study that must be addressed. First, the measure of substance use was obtained from one or both of the following scenarios: a) voluntarily recorded by the patient and b) documented by the physician. There were no methods to document the amount of alcohol consumed or measures of bodily fluids (blood or urine) for verification purposes. Although this may underrepresent the problem, self-reported consumption has been shown to provide accurate estimates. . $^{33,34}$

Second, there is no indication of who was altered by the substance (i.e., the patient or another individual). Consequently, this report should be considered representative of the role alcohol and other drugs play directly and indirectly in injuries in Canada.

Third, the Central region (i.e., Ontario and Quebec) was the only region in which information regarding alcohol-related injuries among youth aged 20-24 years was captured in the CHIRPP database, and, as such, the findings may not be generalizable to the rest of Canada.

Fourth, because forms are completed by different individuals across the country (e.g., physicians, CHIRPP coordinators) there is a possibility of bias in data recording across different hospitals.

Last, fatal injuries are also underrepresented because people who die before presenting to the hospital may not be recorded in the data set. ${ }^{35}$

Nonetheless, past CHIRPP studies ${ }^{28,35}$ have found the data to be of high quality, with only minor systematic errors in data capture. Despite these recognized limitations, the CHIRPP data set offers a novel look at alcohol-related injury patterns, and, if anything, provides a conservative estimate of the burden of alcoholrelated injury among Canadian youth.

\section{CONCLUSION}

Although they represent only a small proportion of all injuries, alcohol-related injuries are an unnecessary burden on the Canadian health care system. Given the large proportion of individuals younger than 15 years in the CHIRPP database, and the conservative measure of substance use, the true prevalence of alcohol-related injuries among youth is likely underestimated. There appears to be an increasing trend in alcohol-related injuries in Canada among adolescents and young adults, and this increase highlights the importance of continuing prevention and educational efforts (i.e., Prevent Alcohol and Risk-related Trauma in Youth [PARTY] program) aimed at reducing alcohol consumption among youth, particularly in situations conducive to injury. ${ }^{36}$ Efforts to monitor trends in alcohol and other drugrelated injury through patient self-report and physician measures should continue as should evaluation of interventions to reduce these statistics.

Acknowledgements: This research was supported by a grant from AUTO21, a member of the Networks of Centres of Excellence program, which is administered and funded by the Natural Sciences and Engineering Research Council, the Canadian Institutes of Health Research and the Social Sciences and Humanities Research Council in partnership with Industry Canada.

Competing interests: None declared.

\section{REFERENCES}

1. Public Health Agency of Canada. Leading causes of death and hospitalization in Canada. 2004. Available: www.phac-aspc.gc .ca/publicat/lcd-pcd97/table1-eng.php (accessed 2009 May 26).

2. Cherpitel CJ. Alcohol and injuries: a review of international emergency room studies. Addiction 1993;88:923-37.

3. Cherpitel CJ, Giesbrecht N, Macdonald S. Alcohol and injury: a comparison of emergency room populations in two Canadian provinces. Am J Drug Alcohol Abuse 1999;25:743-59.

4. Canadian Public Health Association. Creating conditions for bealth. Ottawa (ON): The Association; 2001. Available: www.cpha.ca/en/programs/policy.aspx (accessed 2009 May 26).

5. Centers for Disease Control and Prevention. Conference proceedings on alcohol- and drug-related injuries. Available: www.cdc.gov/ncipc/Spotlight/2003_Alcohol_Conference _Proceedings.htm (accessed 2009 Jun 1).

6. World Health Organization. World Report on child injury prevention. Geneva (CH): The Organization;2008. Available: http://whqlibdoc.who.int/publications/2008/9789241563574 _eng.pdf (accessed 2009 Jun 1).

7. Elder RW, Shults R, Swahn M, et al. Alcohol-related emergency department visits among people ages 13 to 25 years. J Stud Alcohol 2004;65:297-300.

8. Meropol SB, Moscati R, Lillis K, et al. Alcohol-related injuries among adolescents in the emergency department. Ann Emerg Med 1995;26:180-6. 
9. Macdonald S, Wells S, Biesbrecht N, et al. Demographic and substance use factors related to violent and accidental injuries: results from an emergency room study. Drug Alcobol Depend 1999;55:53-61.

10. Charalambous MP. Alcohol and the accident and emergency department: a current review. Alcohol 2002;37:307-12.

11. Institute of Alcohol Studies. Alcohol and bealth. Available: www.ias.org.uk/resources/factsheets/factsheets.html (accessed 2009 May 26).

12. Hingson R, Howland J. Alcohol as a risk factor for injury or death resulting from accidental falls: a review of the literature. J Stud Alcobol 1987;48:212-9.

13. Hingson R, Howland J. Alcohol and non-traffic unintended injuries. Addiction 1993;88(877-883):877-883.

14. Kurzthaler I, Wambacher M, Golser K, et al. Alcohol and benzodiazepines in falls: an epidemiological view. Drug Alcohol Depend 2005;79:225-30.

15. Honkanen R, Ertama L, Kuosmanen P, et al. The role of alcohol in accidental falls. J Stud Alcohol 1983;44:231-45.

16. Hufford MR. Alcohol and suicidal behavior. Clin Psychol Rev 2001;21:797-811.

17. Macdonald S, Cherpitel C, Borges G, et al. The criteria for causation of alcohol in violent injuries based on emergency room data from six countries. Addict Behav 2005;30:103-13.

18. Sher L. Alcohol consumption and suicide. QJM 2006;99:57-61.

19. Cherpitel CJ, Borges G, Wilcox H. Acute alcohol use and suicidal behavior: a review of the literature. Alcohol Clin Exp Res 2004;28:18S-28S.

20. Adcock AG, Nagy S, Simpson J. Selected risk factors in adolescent suicide attempts. Adolescence 1991;26:817-28.

21. Hulse GK, Robertson S, Tait R. Adolescent emergency department presentations with alcohol- or other drug-related problems in Perth, Western Australia. Addiction 2001;96:1059-67.

22. Hawton K, Rodham K, Evans E, et al. Deliberate self harm in adolescents: self report survey in schools in England. BMJ 2002;325:1207-11.

23. Hawton K, Fagg J. Deliberate self-poisoning and self-injury in adolescents. a study of characteristics and trends in $\mathrm{Ox}-$ ford, 1976-89. Br J Psychiatry 1992;161:816-23.

24. Woolfenden S, Dossetor D, Williams K. Children and adolescents with acute alcohol intoxication/self-poisoning presenting to the emergency department. Arch Pediatr Adolesc
Med 2002;156:345-8.

25. Health Canada. Canadian Addiction Survey: A national survey of Canadians' use of alcobol and other drugs. 2005. Available: www.hc-sc.gc.ca/hl-vs/pubs/adp-apd/cas-etc/youth-jeunes/chap1 -eng.php (accessed 2009 May 26).

26. Loiselle JM, Baker M, Templeton J, et al. Substance abuse in adolescent trauma. Ann Emerg Med 1993;22:1530-4.

27. Macarthur C, Pless IB. Evaluation of the quality of an injury surveillance system. Am J Epidemiol 1999;149:586-92.

28. Pless IB, Magdalinos H, Hagel B. Risk-compensation behavior in children: Myth or reality? Arch Pediatr Adolesc Med 2006;160:610-4.

29. Roche A, Watt K, McClure R, et al. Injury and alcohol: a hospital emergency department study. Drug Alcobol Rev 2001;20:155-66.

30. Kresnow M, Powell K, Webb K, et al. Assigning time-linked exposure status to controls in unmatched case-control studies. alcohol use and nearly lethal suicide attempts. Stat Med 2001;20:1479-85

31. Li G, Penelope M, Rothman R, et al. Epidemiology of alcoholrelated emergency department visits. Acad Emerg Med 1998;5:788-95.

32. Baskin-Sommers A, Sommers I. The co-occurrence of substance use and high-risk behaviors. J Adolesc Health 2006;38: 609-11.

33. Cherpitel C. Breath analysis and self-reports as measures of alcohol-related emergency room admissions. I Stud Alcohol 1989;50:155-61.

34. Del Boca FK, Noll J. Truth or consequences: the validity of self-report data in health services research on addiction. Addiction 2000;95:347-60.

35. Pickett $W$, Brison R, Mackenzie S, et al. Youth injury data in the Canadian Hospitals Injury Reporting and Prevention Program: Do they represent the Canadian experience? Inj Prev 2000;6:9-15.

36. SmartRisk. PARTY: prevent alcohol and risk related trauma in youth [home page]. Available: www.partyprogram.com/ (accessed 2009 May 26).

Correspondence to: Dr. Mark Asbridge, Department of Community Health and Epidemiology, Dalhousie University, 5790 University Ave., Halifax NS B3H 1V7; mark.asbridge@dal.ca 